\title{
Significant $P$ wave conversions from upgoing $S$ waves generated by very deep earthquakes around Japan
}

\author{
B. L. N. Kennett ${ }^{1}$ and T. Furumura $2^{2^{*}}$ (D)
}

\begin{abstract}
An important component of the seismic wavefield at moderate epicentral distances from deep earthquakes comes from seismic waves that are radiated upwards from the source. For very deep events, there is a range of distances at which upgoing $\mathrm{S}$ can convert into $\mathrm{P}$ waves that travel in the crust or in the upper mantle as the sPn phase. For a 600-km-deep event, sPn becomes a precursor to S from about $8^{\circ}$, and can have significant amplitude if the source radiation pattern is favourable. These conversions to crustal $P$ have a very similar travel time property to $S$, and interfere strongly with $S$ to produce complex wavetrains on both vertical and radial components. Where the locus of conversion falls on thicker continental crust, S waves can be coupled into partially trapped $\mathrm{P}$ waves in the crust that produce a long-period shear-coupled PL (s-PL) wave. Such longer period phases generated by large, very deep earthquakes can make a major contribution to sustaining large ground motion for considerable distances from the source. Observations of three very deep (>575 km) events around Japan demonstrate the range of propagation effects associated with S to P wave (sP) conversion that plays an important role in shaping the later part of the recorded seismograms. The influence of sP conversion on the observed seismograms and the development of the s-PL wave depend on the variation of crustal thickness along the path and epicentral distance, and particularly on the locus of the conversion zone and the properties of the crust at that location.
\end{abstract}

Keywords: Deep earthquakes, S to P conversion, sP phases, Shear-coupled PL wave, Guided waves in subducting plate

\section{Introduction}

Most shallow earthquakes have a concentrated zone of strong ground motion in the immediate vicinity of the epicentre, but deeper events spread their effects more widely at moderate epicentral distances $(>1000 \mathrm{~km})$. The largest very deep earthquakes such as the 2013 Sea of Okhotsk event $(610 \mathrm{~km}, \mathrm{Mw} 8.2)$ and the 2015 Ogasawara event $(680 \mathrm{~km}, \mathrm{Mw} 7.9)$ produce significant effects across the whole span of the Japanese islands, though the hypocenters were located more than a thousand kilometres from the main Japanese islands.

In this study, we examine the nature of the seismic wavefield caused by three very deep earthquakes around

\footnotetext{
* Correspondence: furumura@eri.u-tokyo.ac.jp

${ }^{2}$ Earthquake Research Institute, The University of Tokyo, 1-1-1 Yayoi,

Bunkyo-ku, Tokyo 113-0032, Japan

Full list of author information is available at the end of the article
}

Japan that produce contrasting patterns of strong ground motion (Fig. 1).

Since such deep events are associated with subduction of the Pacific Plate, a component of the seismic energy release is ducted to the surface by the high-velocity and lowattenuation environment of the slab, leading to notable concentrations of ground motion on the Pacific Ocean side in the forearc zone of the slab, particularly for acceleration. The high-frequency $(>1 \mathrm{~Hz})$ characteristics of such ground motion are consistent with the presence of a stochastic waveguide in the subducted plate, associated with a heterogeneity distribution with much longer correlation lengths along the slab than perpendicular (Furumura and Kennett, 2005). Such quasi-laminar heterogeneity in the Pacific plate acts as an efficient waveguide only for highfrequency signals and has no effect on longer wavelengths at low frequencies. 


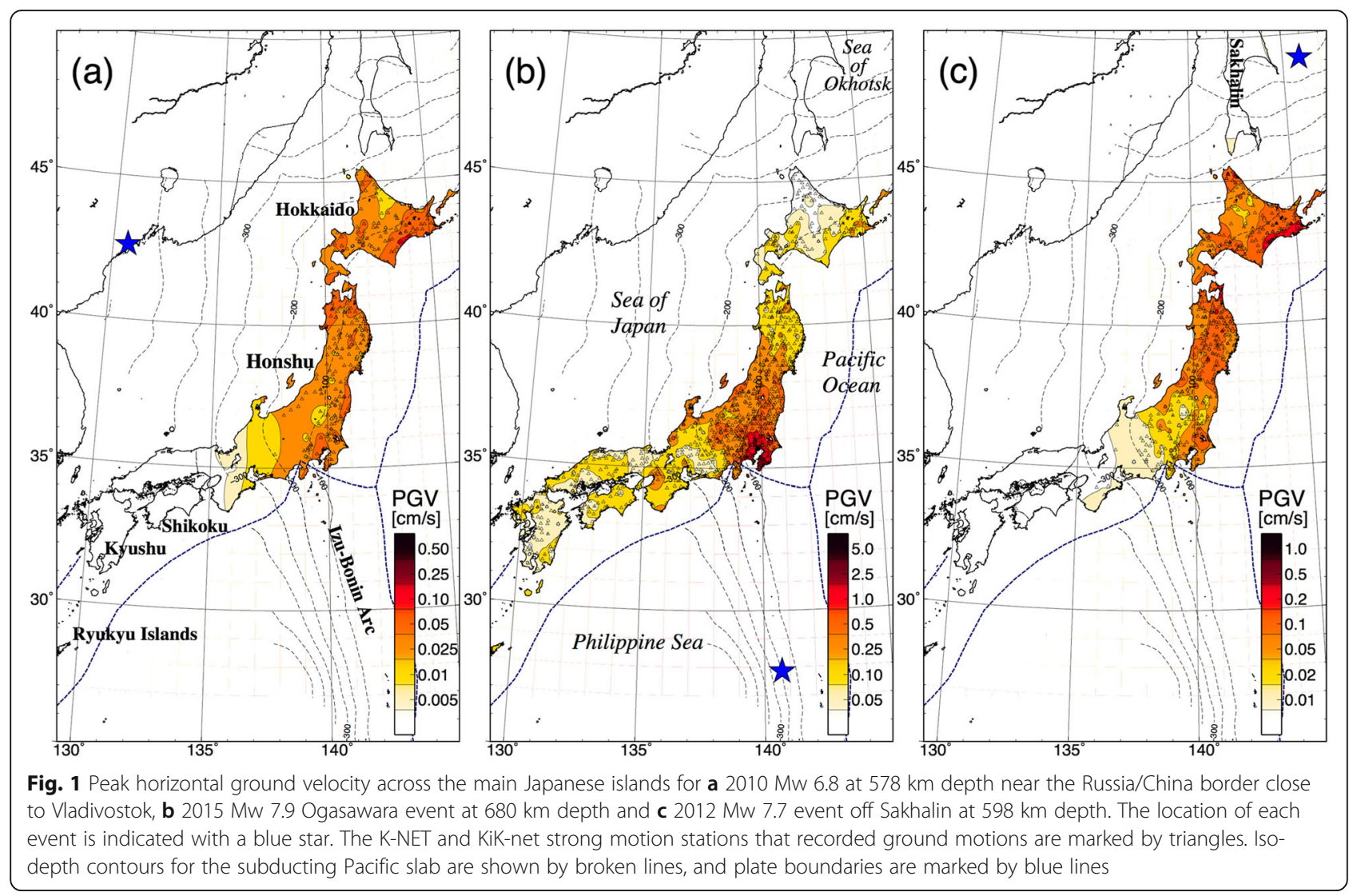

The complex configuration of the subducting Pacific plate leads to variations in propagation efficiency for these high-frequency arrivals (Kennett and Furumura 2010). The largest effects occur in propagation directly up-slab. Oblique-guided wave propagation traversing the subduction zone nearly horizontally is less efficient, but still carries high-frequency $\mathrm{P}$ and $\mathrm{S}$ arrivals. By no means, all the seismic energy arriving at regional distances is involved with slab-guided propagation of high-frequency waves. Seismic energy travelling outside the slab from very deep earthquakes can make significant contributions to the overall ground motion (Chen et al. 2007), especially for lower frequencies $(<1 \mathrm{~Hz})$. The onset of lower frequency energy travels by Fermat paths, i.e., the fastest possible path between source and receiver, and so constitutes the first arrival for each phase. Guided waves normally follow because they take a longer path even though most is in a higher wavespeed medium.

Frequently, a major contribution to the wavefield comes from sP conversions, with upward propagating $\mathrm{S}$ waves from the deep sources interacting with nearsurface structure to produce a variety of propagation effects. When the surface interaction zone is in continental crust, $\mathrm{S}$ waves can couple into $\mathrm{P}$ waves in the thicker crust that interfere to produce a long-period wavetrain (shear-coupled PL; s-PL) following S, which can travel for several hundred kilometres in the crustal waveguide (Furumura and Kennett 2017). Such longer period phases generated by large, very deep earthquakes can make a major contribution to sustaining large ground motion for considerable distances from the source. The $\mathrm{s}$-PL phase can also be generated in the oceanic environment, but then the frequency is higher in the thinner crustal waveguide. More commonly, there is conversion from upgoing $\mathrm{S}$ to $\mathrm{P}$ body wave arrivals, travelling in the crust or uppermost mantle (sPn). The nature of the conversion process depends on the thickness of the crust, the depth of sea water and sea bed contrasts in a somewhat complex manner.

In this study, we will examine the properties of the longer-period $\mathrm{P}$ converted phases generated by upward travelling $\mathrm{S}$ wave from deep earthquakes, based on analysis of the F-net broadband, strong motion records across Japanese islands, and complemented by numerical simulation of seismic wave propagation. Observations of large, very deep events around Japan display a variety of behaviour in SP conversion and S-PL waves, which on occasion can carry the largest ground velocity. The variations in the patterns of ground motion carried by these sP converted phases can be expected to be linked to the location of the conversion zone, and the variations in crustal thickness across the region. We will examine this 
by numerical simulation of seismic wave propagation and comparison with observed ground motions.

\section{Methods/Experimental}

Our approach is to exploit the rich suite of observations of the deep events across the Japanese Islands using the broadband F-net stations, supplemented by the dense Knet and KiK-net strong ground motion stations. We use the strong ground motion results to build the patterns of ground velocity and acceleration associated with the events, and examine the detail of the wavefield from the broadband seismograms. We exploit the source characterization of the events from the global centroid moment tensor catalogue, and construct a 3-D model for the whole region using the best available information on crustal structure, the configuration of the subducting Pacific plate and tomographic results on the distribution of seismic wavespeeds. All this information is used in 2D modelling along carefully chosen cross-sections using the OpenSWPC finite difference code (Maeda et al. 2017). The cross-sections are chosen to reflect the patterns of selected stations. The large events are likely to have complex source time functions, associated with multiple sub-events to create complex and long wave packets. However, we find that the major characteristics of the propagation processes, especially for the longperiod wavefield, can be well represented by a point source with a relatively simple source pulse.

\section{Nature of the seismic wavefield from very deep events} We here consider the character of the wavefield produced by very deep events, and look at the conditions that affect conversion of the upgoing $\mathrm{S}$ waves into $\mathrm{P}$ wave arrivals. The main phase arrivals expected are illustrated in Fig. 2, for an event at $600 \mathrm{~km}$ using the ak135 model (Kennett et al. 1995) which has a continental crust $35 \mathrm{~km}$ thick. A schematic illustration of the ray paths for the major phases from the deep source is illustrated in Fig. 3.

Out to $10^{\circ}$ epicentral distance, all contributions to the wavefield are associated with waves that are radiated upwards from the deep source (Pup and Sup in Fig. 2). These upgoing $\mathrm{P}$ and $\mathrm{S}$ waves extend out to close to $19^{\circ}$ epicentral distance, but are overtaken at around $14^{\circ}$ by waves radiated downward from the source. These downgoing waves are refracted back from beneath the source, with a triplication associated with interaction with the ' $660 \mathrm{~km}$ ' discontinuity (the ' $\mathrm{z}$ ' shape in the slowness and the multiple close arrivals in the travel time plot in Fig. 2). The result of the interaction of both upward and downward radiated waves is a steady change in the character of the $\mathrm{P}$ and $\mathrm{S}$ arrivals over the interval from 11 to $18^{\circ}$, which is captured by many stations in the Japanese Islands for deep events in the Pacific Plate.

From 4 to $6^{\circ}$, the upgoing $S$ waves have appropriate slowness to be able to convert to $\mathrm{P}$ waves (sP) travelling in the upper mantle and from 6 to $8^{\circ}$ to produce crustally
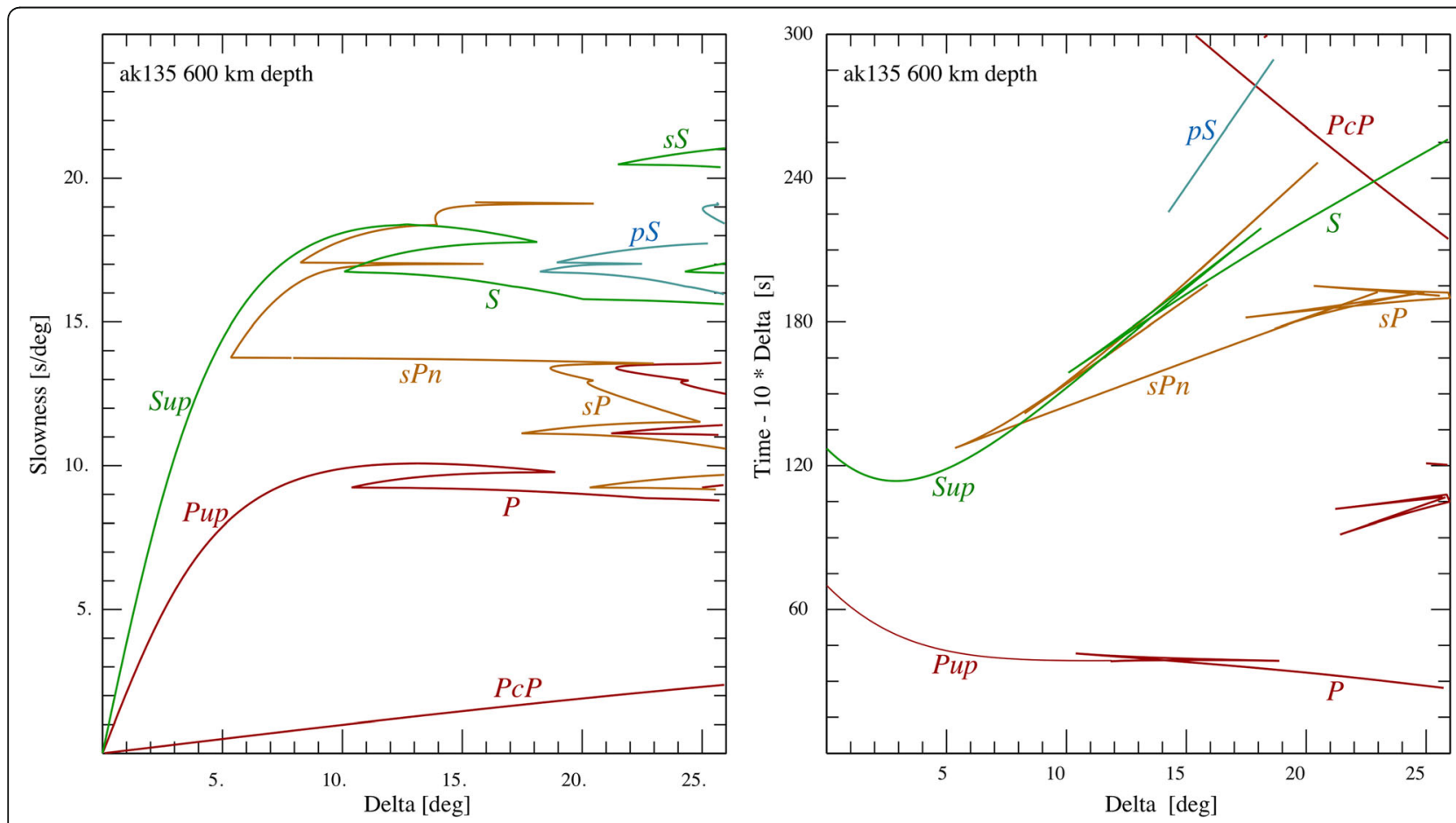

Fig. 2 Summary of propagation characteristics of major P and S phases and converted phases at the free surface for a 600-km-deep source using the ak135 velocity model (35 km crust), for both slowness (left) and travel time (right) as a function of distance (Delta) 


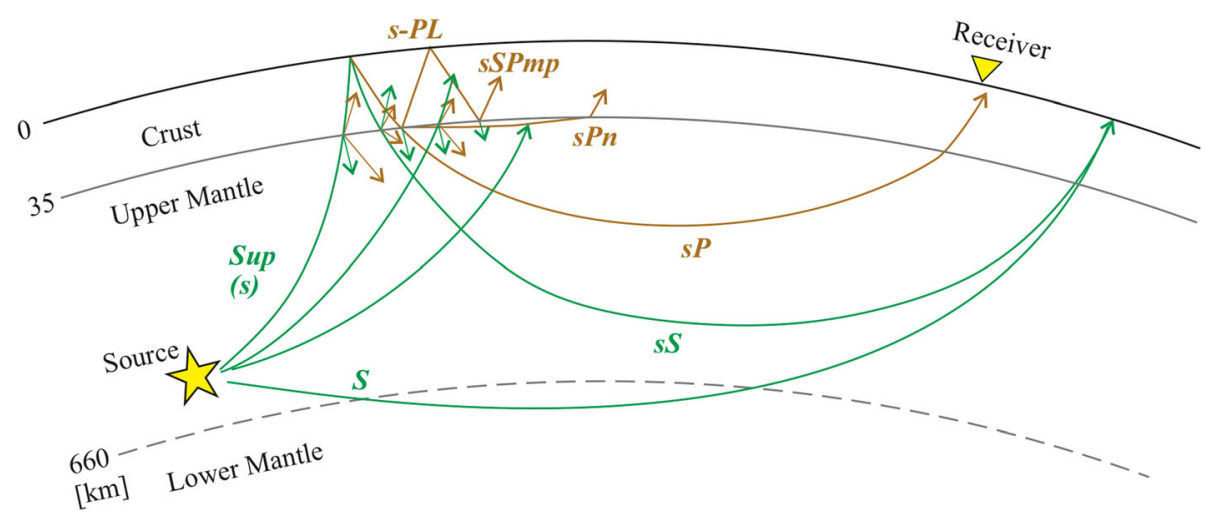

Fig. 3 Schematic illustration of the raypaths for major seismic phases from a very deep source: upgoing S wave (Sup, s), downgoing S wave, surface reflected $\mathrm{SS}$ and $\mathrm{SP}, \mathrm{sPn}$ waves and multiple $\mathrm{SSP}$ mp reflections in the crust are marked. Horizontally travelling sSPmp multiples in the crust couple with the incoming $S$ wave $(\mathrm{s})$ develop the s-PL phase

guided $\mathrm{P}$ waves. Coupling into the $\mathrm{sS}$ phase which is refracted back from the mantle structure starts at about $9^{\circ}$. But these $\mathrm{sS}$ arrivals do not reach the surface again until about $23^{\circ}$ epicentral distance. The conversion zones enlarge with increasing source depth and can be mapped out by examining the distance range spanned by waves with slownesses between 13.7 and $13.2 \mathrm{~s} /{ }^{\circ}$, corresponding to upper mantle propagation, in an analogous way to the treatment of s-PL waves in the Fig. 13 of Furumura and Kennett (2017).

The position of the source relative to the $660 \mathrm{~km}$ discontinuity does not have any effect on the converted phases, but does modify the nature of the $\mathrm{P}$ and $\mathrm{S}$ waves that leave the source downwards. As the source approaches the $660 \mathrm{~km}$ discontinuity, the triplications in $\mathrm{P}$ and $\mathrm{S}$ weaken and the associated waveform becomes less complex.

The features of the seismograms recorded at the surface depend strongly on the conditions around the conversion zone for upgoing $\mathrm{S}$. We illustrate a range of such effects in Fig. 4 with 2-D finite-difference method (FDM) modelling using modifications of the ak135 velocity model in the top $50 \mathrm{~km}$, varying the thickness of the crust $(12,20,35$ and $50 \mathrm{~km})$. The oceanic crustal model has $5 \mathrm{~km}$ of sea water on top of a $7 \mathrm{~km}$ crust.

The calculation domain extended $4400 \mathrm{~km}$ horizontally and $4000 \mathrm{~km}$ radially (into the outer core), with a grid size of $0.4 \mathrm{~km}$. The source employed was a combination of an explosion and a torque source at $600 \mathrm{~km}$ depth, which produces isotropic $\mathrm{P}$ and $\mathrm{S}$ radiation to avoid extra complications from source radiation effects. The pseudo-delta function source has a peak frequency of $0.5 \mathrm{~Hz}$. The FDM simulation is conducted in a Cartesian-coordinate system. Earth flattening is applied to compensate for the sphericity of the Earth.

At the shortest epicentral distance $\left(7.9^{\circ}-878 \mathrm{~km}\right)$, all the arrivals are associated with upgoing $\mathrm{P}$ or $\mathrm{S}$ waves from the source, so that the basic pulse is quite sharp as can be seen for the $\mathrm{P}$ waves with continental crust. In the presence of seawater-top trace in Fig. $4 \mathrm{a}$-there is considerable reverberation with $\mathrm{P}$ waves reflected at both the sea bed and the sea surface; the result is an elongated wavetrain with lower frequencies associated with the wave interference in the water. For these calculations, we have assumed a sharp transition from water $(\mathrm{Vp}=1.5 \mathrm{~km} / \mathrm{s})$ to hard rock $(\mathrm{Vp}=5.8 \mathrm{~km} / \mathrm{s})$, but in the presence of sediments, we can expect the $\mathrm{P}$ reverberation train to be somewhat muted.

This epicentral distance $(878 \mathrm{~km})$ lies close to the crossover between $\mathrm{S}$ and sPn as first arrivals (Fig. 4a). As the thickness of the continental crust increases, the coda of the $\mathrm{P}$ waves becomes longer, and the $\mathrm{S}$ waveform more complex with $\mathrm{S}$ crustal reflections interacting with converted P waves. The separation of $\mathrm{S}$ and $\mathrm{sPn}$ is greater for the thicker crust, and the largest contribution to the complex wave shape comes from sPn. For thicker crust, there is also more interaction with crustal P leading a complex coda to $\mathrm{S}$.

In contrast, at moderate epicentral distance $\left(13.9^{\circ}-\right.$ $1535 \mathrm{~km})$, the converted phase sP is well separated from $\mathrm{S}$ (Fig. 4b). Both the P and S waveforms show broadening from the effects of the triplication associated with the $660 \mathrm{~km}$ discontinuity, and the switch over between arrivals from upgoing and downgoing radiation at the source. For the thicker crust, the longer period s-PL train forms a distinct follower to $\mathrm{S}$ itself. This $\mathrm{s}$-PL wavetrain builds up away from the conversion zone and has longer duration for thicker crust (Furumura and Kennett 2017).

At larger epicentral distance $\left(18.8^{\circ}-2083 \mathrm{~km}\right)$, the triplication of the $\mathrm{P}$ waves becomes very evident giving a chain of $\mathrm{P}$ pulses (Fig. 4c). The conversion $\mathrm{sP}$ is now well separated from $\mathrm{S}$ and the normally dispersed s-PL wavetrain following $\mathrm{S}$ has longer duration for thicker 

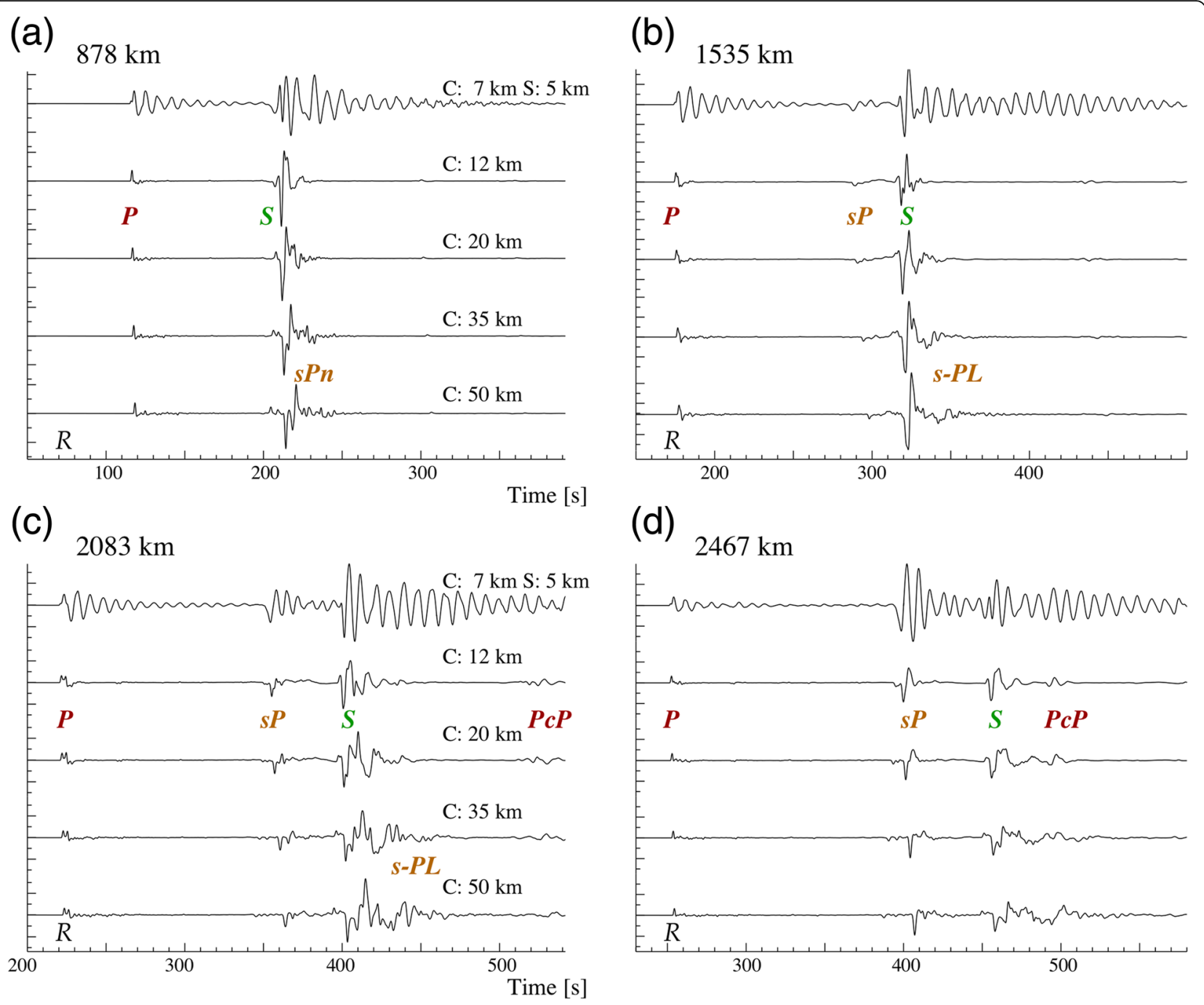

Fig. 4 Comparison of synthetic waveforms for the $R$ component of ground velocity for a 600-km-deep source, for modifications of the ak 135 model with varying near surface structure. The top trace includes $5 \mathrm{~km}$ of sea water on top of a $7 \mathrm{~km}$ crust with recording at the seabed, and the other traces represent progressively thickening continental crust up to $50 \mathrm{~km}$ thickness. Four epicentral distances are shown: a $878 \mathrm{~km}\left(7.89^{\circ}\right)$ where the $\mathrm{P}$ and $\mathrm{S}$ phases are produced solely by upgoing waves, $\mathbf{b} 1535 \mathrm{~km}\left(13.80^{\circ}\right)$ where there is interference between waves that have left the source both upwards and downwards to produce more complex waveforms, c $2083 \mathrm{~km}\left(18.73^{\circ}\right)$ where sP becomes a distinct phase and $\mathbf{d}$ $2467 \mathrm{~km}\left(22.19^{\circ}\right)$ where $\mathrm{SP}$ is as large as or larger than the S phase. At the larger distances, there is a clear separation of converted phases

crust. Even further away from the source $\left(22.2^{\circ}-\right.$ $2467 \mathrm{~km}$ ), the size of the sP conversion is as large as or larger than $\mathrm{S}$ phase (Fig. 4d). The PcP wave reflected back from the core arrives just behind $\mathrm{S}$ and can merge into the s-PL wavetrain for thicker crust.

From a range of simulations for different crustal structure models, we can confirm that the characteristics of the $\mathrm{sP}$ converted phases are imprinted in the zone of conversion, and so are dictated by the character of the crust in that location. As the converted phases propagate to larger distances, they are influenced by the structures through which they pass, but unless they encounter very strong structural contrasts tend to retain their character.

\section{Results and Discussion}

Observations of very deep events across the Japanese Islands

We now examine the patterns of observed seismograms for the three events shown in Fig. 1, recorded at a common set of stations from northern Hokkaido through to the southern Ryukyu islands. These results confirm the characteristics of the wavefield from very deep earthquakes based on our theoretical results and numerical experiments. Conversions from upgoing $\mathrm{S}$ waves make a distinct contribution to the wavefield seen across the Japanese islands.

In Fig. 5, we show the configuration of the sources and the F-net broadband, strong-motion stations, and in 


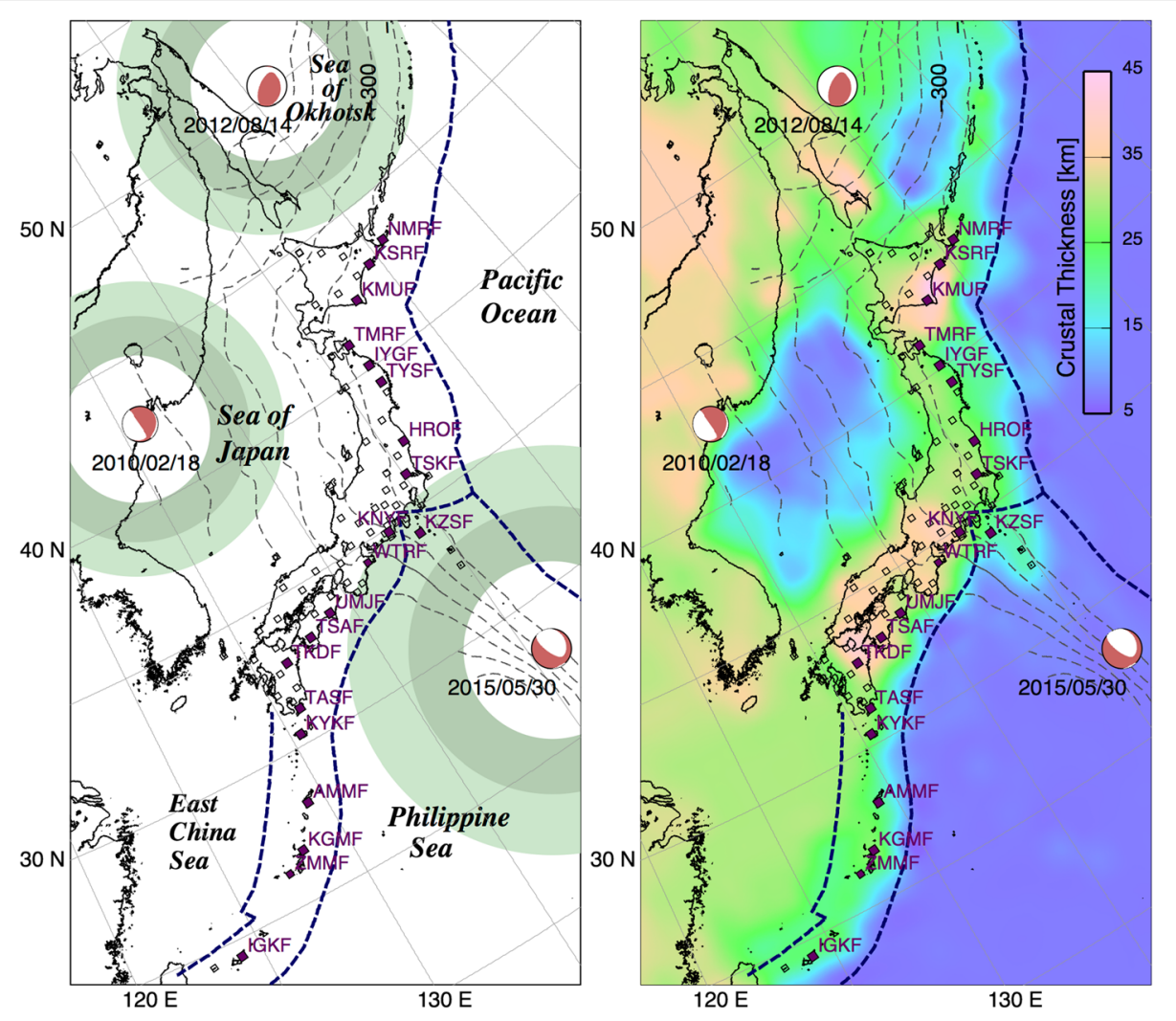

Fig. 5 Configuration of very deep earthquakes and F-net stations, superimposed on crustal thickness (from CRUST1.0-Laske et al. 2013). The stations displayed in Figs. 6,7 and 8 are annotated and have filled symbols. The zone of conversion from upgoing $S$ to $P$ is indicated for upper mantle propagation $(\mathrm{s} \mathrm{Pn})$ in darker tones in the left panel and for crustally guided $\mathrm{P}$ (lighter tones). The size of the conversion zones increases with source depth

Figs. 6, 7 and 8 display the record sections for the three events. In the left-hand panel of Fig. 5, we indicate for each source the surface locations of the bands where conversion can occur from upgoing $\mathrm{S}$ to upper-mantle and crustal $\mathrm{P}$ arrivals (sPn). The darker zone is that for mantle coupling $(\mathrm{sPn})$, and the lighter for crustal coupling (s-PL). The width of the conversion zones is significantly larger for the very deep event near the Ogasawara Islands $(680 \mathrm{~km})$. The right-hand panel of Fig. 5 displays crustal thickness from model CRUST1.0 (Laske et al. 2013), so that the locations of the conversion zones relative to crustal structure can be assessed.

For each event, we present record sections for the horizontal component recordings of ground velocity at a common set of stations, and track the balance of the wavefield between the components. In Figs. 6, 7 and 8, we show horizontal velocity records for traces rotated to the great-circle between source and receiver $(R)$ and in the transverse direction $(T)$. The times of the expected arrivals from the ak135 model are indicated.

If Earth structure were purely one-dimensional, with just radial variation, the $T$ component would comprise just $\mathrm{SH}$ waves, with P-SV interactions confined to the $R$ component. The effect of 3-D structure, in the presence of subducting plates, is to distort propagation paths with some $\mathrm{P}$ wave energy appearing on the $T$ component. Yet, conversion from upgoing $\mathrm{S}$ to $\mathrm{P}$ is almost entirely confined to the $R$ component. Vertical component records generally have a similar character to the $R$ component, with somewhat enhanced $\mathrm{P}$ waves.

\section{Vladivostok event}

This modest size event ( $\mathrm{Mw}$ 6.8) beneath the ChinaRussia border close to Vladivostok occurred at $578 \mathrm{~km}$ depth and produces a concentration of ground motion along the eastern seaboard of northern Honshu and Hokkaido (Fig. 1a), which is even more pronounced in peak ground acceleration (PGA), since the size of the guided energy traversing the slab suggest the presence of some amplification at depth probably due to low velocities associated with a modified olivine wedge (Furumura et al. 2016). The ground velocity shown in Fig. 1a is less strong on the back-arc side of northern Honshu and Hokkaido, and fades into western Japan.

The full suite of horizontal component seismograms at the chain of stations along the Japanese islands is displayed 


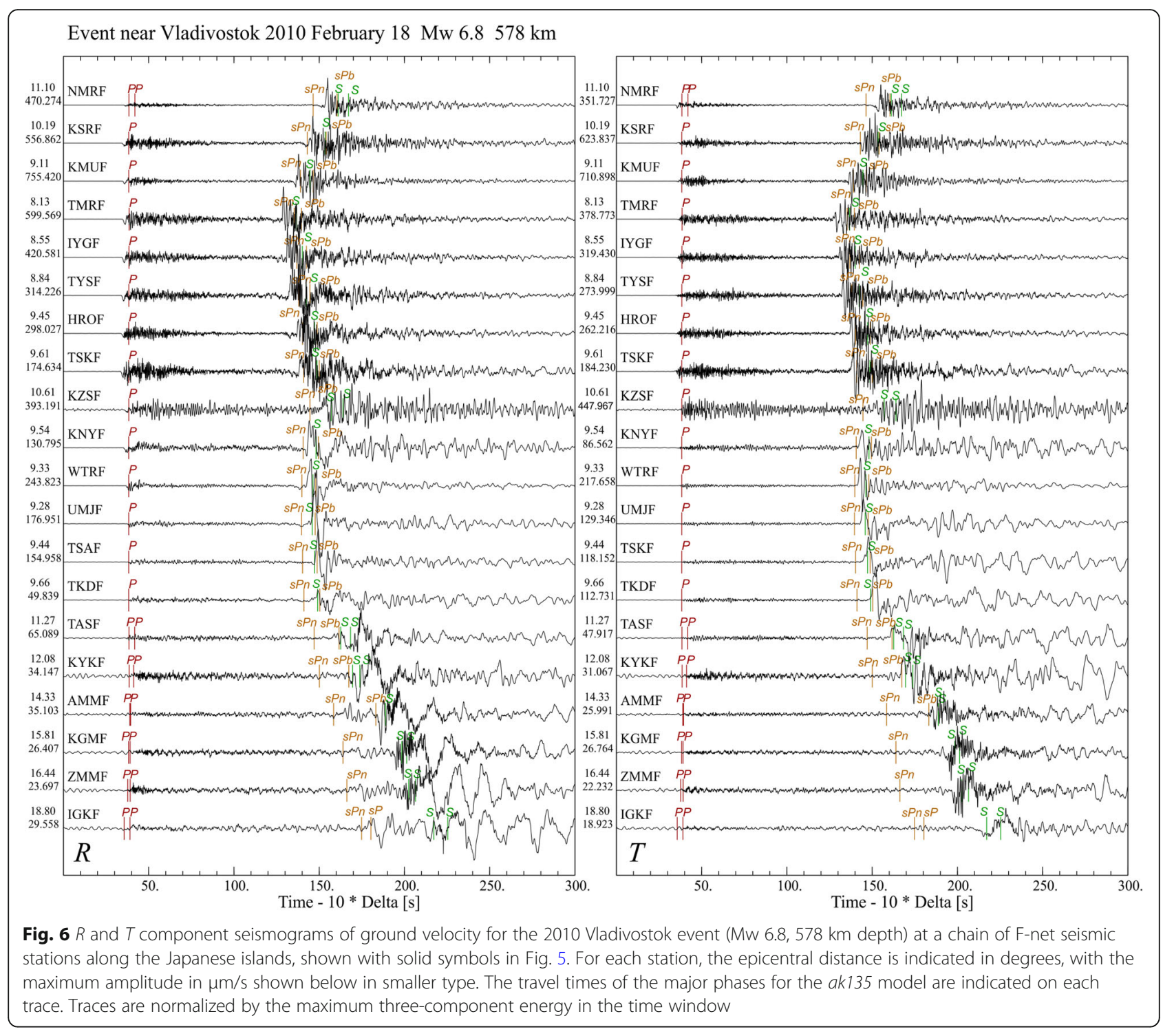

in Fig. 6. The slab-guided waves in northern Japan show markedly higher frequencies $(>1 \mathrm{~Hz}$ ) than elsewhere; they also carry an elongated high-frequency coda. The onset of these seismograms is low frequency $(<1 \mathrm{~Hz})$ representing waves travelling outside the slab, followed within a few seconds by high-frequency scattered waves trapped in the slab that appear on all components. This pattern is very clear in the $\mathrm{P}$ arrivals, and for $\mathrm{S}$ at stations NMRF and KSRF in Hokkaido. From stations IYGF to TSKF in Honshu, there is a medium-frequency precursor to the $S$ wave train from $S$ to $\mathrm{P}$ conversion at the base of the crust.

The waveforms for $\mathrm{SH}$ on the $T$ component are relatively simple for western Japan (Honshu, Shikoku) with lower frequencies associated with propagation through the back arc region outside the subducted slab. However, the pulse forms are modified on the $R$ component by the presence of converted $\mathrm{P}$, with the conversion zone lying beneath the Sea of Japan.

As the epicentral distance increases from western Kyushu into the Ryukyu islands, a distinct sP arrival emerges before $\mathrm{S}$ and is rather prominent at the most distant stations as sPn. The conversion zone for the arrivals at these far stations lies in the continental crust of the Korean peninsula. Distinct long-period s-PL trains are built up as the waves traverse the shallow seas behind the Ryukyu arc, with some elongation of the wavetrain from reverberations in deeper $(>5 \mathrm{~km}$ ) water close to the receivers. There are also hints of higher-frequency slab-guided waves from energy that has coupled into the Philippine Sea plate, descending beneath western Japan, and then propagated to the surface. The paths to these southern stations avoid much of the enhanced attenuation in the mantle wedge for the Pacific 


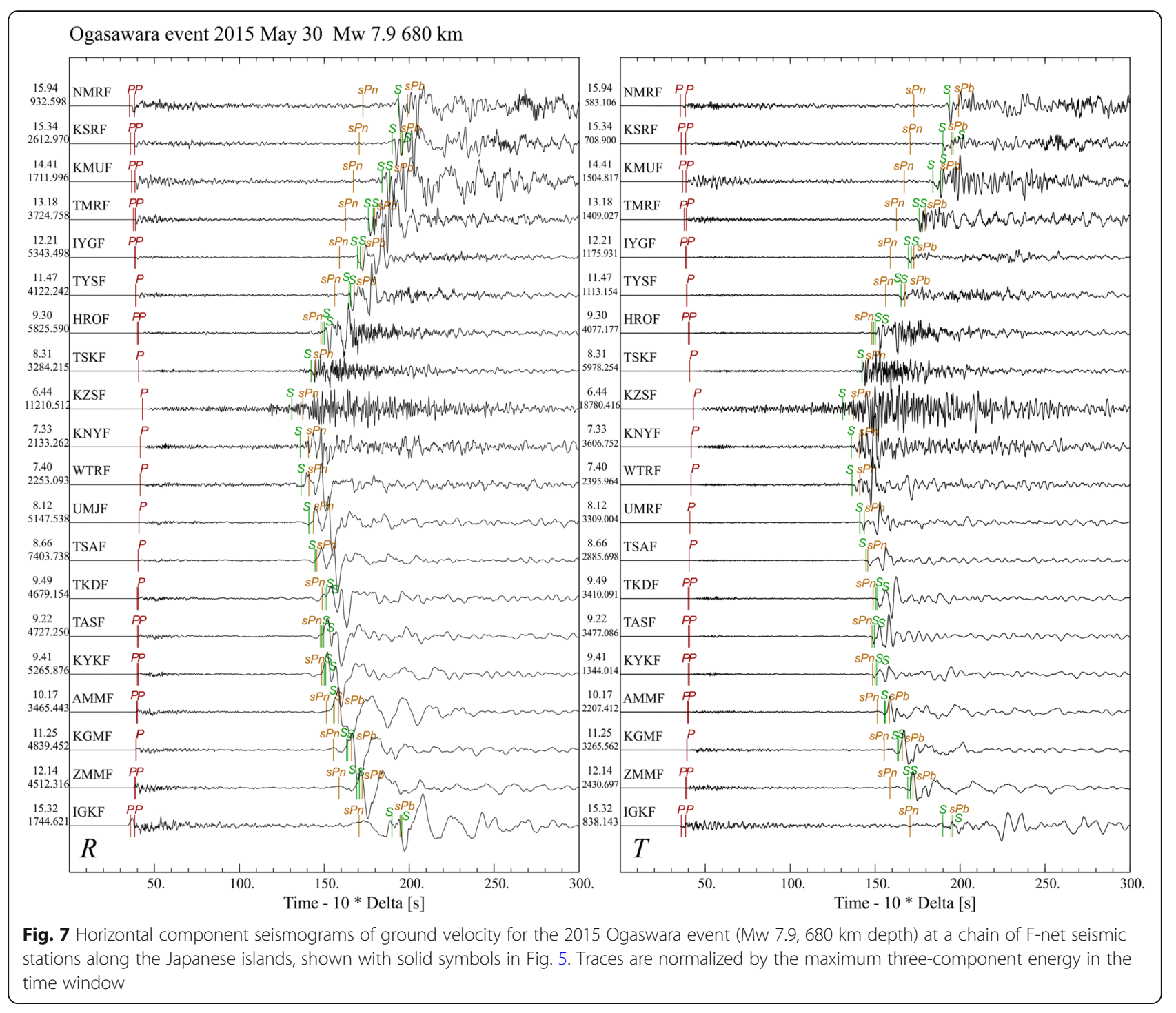

Plate, and are thus able to retain higher frequency components.

\section{Ogasawara event}

This very deep $(680 \mathrm{~km})$ earthquake produced significant ground motions across the whole of the Japanese islands (Fig. 1b). The source of this unusually deep event lies outside the main subducted slab, and Kuge (2017) from detailed analysis of $\mathrm{P}$ waveforms has suggested that it may lie below the local manifestation of the ' $660 \mathrm{~km}$ ' discontinuity. The location of the event below the main subducted slab means that coupling into slab-guided waves is inefficient, and across Japan much of the strongest ground motion is associated with conversion from upgoing $\mathrm{S}$ waves to multiple $\mathrm{P}$ reflections in the crust $(\mathrm{sSPmP})$ and s-PL (Furumura and Kennett 2017).

Limited guided wave energy travelling rather obliquely through the Pacific slab reaches as far north as station
TSKF. The $\mathrm{S}$ waves couple into the near surface structure to give a weak contribution on the waveforms further north that travels at wavespeeds less than $4.5 \mathrm{~km} / \mathrm{s}$ (akin to $\mathrm{Sn}$ and $\mathrm{Lg}$ ). This arrival is present on both the $R$ and $T$ components. On the $R$ component, between $\mathrm{S}$ and these crustally guided waves, a well-developed s-PL train with lower frequencies travels through the continental crust. The conversion occurs in the Kanto area around Tokyo, and the waves travel both north and west through Honshu. Dispersion builds up with distance to produce greater complexity of waveform (Furumura and Kennett 2017). The consequence of the presence of the $\mathrm{P}$ conversions produces a remarkable difference in the character of the $S$ wavetrain between the $R$ and $T$ components.

In Shikoku, the $S$ arrivals are comparatively simple for $\mathrm{SH}$ on the $T$ component, but have large contributions a few seconds after $S$ on the $R$ component that arise from sPn (as in the examples in Fig. 4). This sPn arrival is 


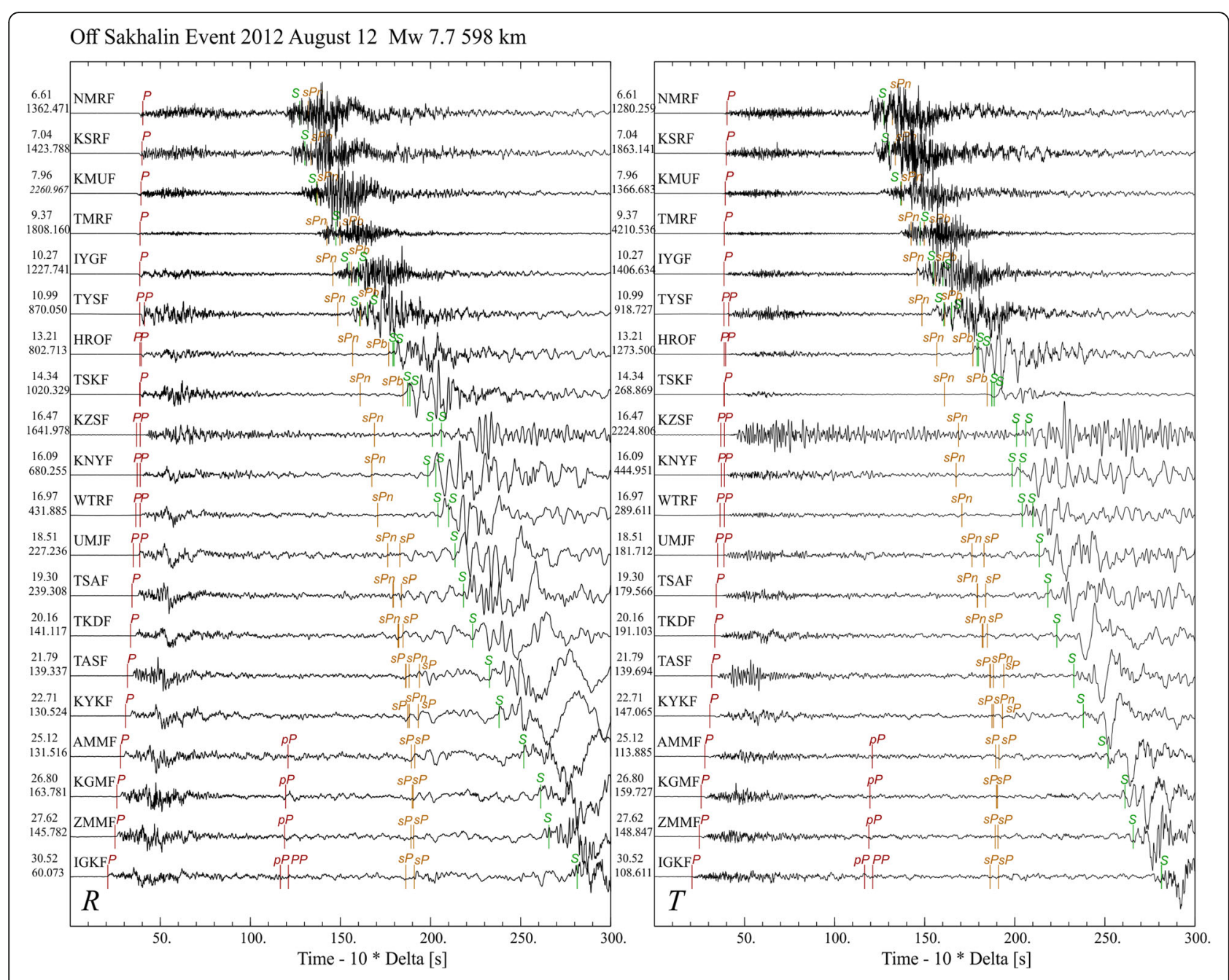

Fig. 8 Horizontal component seismograms of ground velocity for the 2012 Off-Sakhalin event (Mw 7.7, $598 \mathrm{~km}$ depth) at a chain of F-net seismic stations along the Japanese islands, shown with solid symbols in Fig. 5. Traces are normalized by the maximum three-component energy in the time window

followed by the s-PL arrivals that increase in size out to western Kyushu.

Much lower frequency $S$ wavetrains $(<0.1 \mathrm{~Hz})$ are found through the Ryukyu chain. Some of the s-PL from the continent appears to be guided along the island arc, but the onset of $\mathrm{S}$ comes from waves that have traversed the mantle wedge above the Pacific plate subducting under the Izu-Bonin chain. At the far stations near Taiwan, rather long-period $\mathrm{sP}$ arrives before $\mathrm{S}$ and the later part of the wavetrain appears to have some of the character of sPL modulated by significant reverberative effects from long passage through deep sea water, in the same way as seen in Fig. 4. Conversion may be associated with localized areas of thicker oceanic crust in the Philippine Sea.

\section{Off-Sakhalin event}

For this event, at $598 \mathrm{~km}$ depth, the regional wavefield across Japan shows complex $\mathrm{P}$ arrivals because many stations lie in the epicentral distance range with triplications. There is a broad distribution of both peak ground velocity across Tohoku extending south to around $37^{\circ} \mathrm{N}$ (Fig. 1c).

Just as for the deep Ogasawara event of 2015, the dominant effects do not come from slab-guided $\mathrm{S}$ waves but from a combination of other seismic phases. Guided $S$ is the main contributor to ground motion in the east of Hokkaido, but in the west Pwave amplitude exceeds $\mathrm{S}$ and produces the largest ground motion. In Honshu (stations NMRF-TASF), the s-PL phase shows large amplitude relative to both $\mathrm{S}$ and $\mathrm{P}$.

For this deep earthquake, the path through the $\mathrm{Pa}$ cific plate subduction zone to Japanese stations is oblique to the dip of the zone. High-frequency guided waves through the subducted slab are prominent in the Kurile section of the slab in Hokkaido, but are 
disrupted by the complex geometry of the transition into the Honshu section (Miller et al. 2006).

Noticeable changes in seismic waveforms of $\mathrm{P}$ and $\mathrm{S}$ occur at around $14^{\circ}$ from the source, as a switch occurs from the earlier arrival of energy that left the source upwards to that which has been refracted back from below the source level, including interaction with the ' $660 \mathrm{~km}$ ' discontinuity.

The conversion zone for the sP phases lies in the back-arc zone of the Kurile Slab in the Sea of Okhotsk. The nature of the sP conversion depends on the location. Where this occurs closer to the Kurile arc, there can be strong attenuation of the $\mathrm{S}$ wave leg below the Moho and the shallow part of the converted $\mathrm{P}$ wave path. The sP arrivals are quite strong from Shikoku into the northern Ryukyu, beyond $18^{\circ}$ epicentral distance.

The southern stations show a prominent s-PL phase as well as sP. It appears that passage through the thinner crust beneath the Sea of Japan $(<15 \mathrm{~km}$ thickness $)$ has not disrupted the multiple interference of the $\mathrm{P}$ waves in the crust that produces the longer-period resultant. The difference in frequency content in the coda of $S$ at the southern stations between the $\mathrm{R}$ and $\mathrm{T}$ components is particularly striking.

The set of three very deep events in the area around Japan illustrated here all show a major contribution to the wavefield from waves generated by $\mathrm{P}$ wave conversion from upward travelling $\mathrm{S}$, which are prominent on the $R$ and $Z$ components of ground motion. A striking difference from the $T$ component with simpler $\mathrm{SH}$ wave behaviour and no conversion to $\mathrm{P}$ comes with the presence of strong low-frequency s-PL. Nevertheless, nearly all $\mathrm{S}$ wavetrains on the $R$ component display significant modification by interference with the complex of sP arrivals travelling in the crust and mantle. Such longerperiod phases generated by very deep earthquakes made a major contribution to sustaining large, long-duration ground motions for considerable distances from the source that can reach several thousand kilometres (Fig. 1).

The three very deep events around Japan that we have considered cover a range of epicentral distances, and this affects way in which conversions from upgoing $S$ affect the wavefield. There is a broad azimuth range to the set of F-net stations for the Vladivostok and Ogasawara events, and in consequence we can see a range of different behaviour across Japan in the set of record sections. The azimuth range is somewhat smaller for the off-Sakhalin event, so that in this case there is more of an evolution with epicentral distance. The effects of interference between converted sP energy and $\mathrm{S}$ waves on any particular seismogram depend on the epicentral distance, the nature of the conversion zone and, to some extent, on the source radiation pattern.
Strong conversions from upgoing $\mathrm{S}$ waves are a feature of all very deep earthquakes, and tend to become more pronounced as the depth of the source increases because the size of the zones of potential conversion enlarge. Such converted energy at shorter epicentral distance has a very similar travel time to $S$ and so complex interference can occur. As epicentral distance increases, sPn separates as a clear precursor to $\mathrm{S}$, and where conversion has occurred in continental crust an elongated lowfrequency wavetrain follows $\mathrm{S}$ on the $R$ and $Z$ components comprising s-PL waves partially trapped in the crustal waveguide. Thus, the character of the $S$ arrivals is significantly modified by conversions that make a significant contribution to the patterns of ground motion.

The largest known very deep earthquake occurred on 2013 May $24(630 \mathrm{~km}, \mathrm{Mw}$ 8.3) in the Pacific Slab beneath the Sea of Okhotsk near Kamchatka. This event lies another $6^{\circ}$ further away than the off Sakhalin earthquake, but still produced significant ground motion with the Japan Meteorological Agency's Intensity scale 3 (max 7) recorded in Hokkaido at a distance of $1500 \mathrm{~km}$ and also in Tohoku $(2000 \mathrm{~km})$. The area where the event was felt (Intensity >1) spreads even further to western Kyushu $(3500 \mathrm{~km})$. The relatively large epicentral distance to the Japanese islands $(1500-3500 \mathrm{~km})$ means that the emergence of sPn starts in northern Honshu, and this phase is prominent in stations further south. The conversion points for upgoing $\mathrm{S}$ lie in the thinner crust of the Sea of Okhotsk and little long-period s-PL develops. Thus, the broad spread of the felt area across the entire Japanese islands is likely to be caused by large, near-caustic $S$ waves and sP phases reflected from thinner crust beneath the Sea of Okhotsk (Furumura and Kennett 2019).

\section{Conclusions}

Upgoing waves from deep earthquakes make a major contribution to the seismic wavefield, from free-surface reflections and conversions. The epicentral distance range for significant conversion increases with source depth. This means that for very deep events, there is more chance for upgoing $\mathrm{S}$ waves to convert to $\mathrm{P}$ waves that interact with the crust and the uppermost mantle. The strength of the converted phases depends on the locus of the conversion zone and the properties of the crust at that location, and then on the variations of crustal thickness along the path.

At regional to far-regional epicentral distances, significant contributions to the wavefield come from converted $\mathrm{P}$ waves in the crustal waveguide and the $\mathrm{sPn}$ wave that has traversed just below the crust-mantle boundary. The crustal $\mathrm{P}$ phases have a very similar travel time to $\mathrm{S}$, and their interference with the $\mathrm{S}$ coda produces an extended wavetrain of longer-period s-PL waves from partially trapped $\mathrm{P}$ waves in the crust. 
With the aid of the F-net broadband, strong motion network deployed across Japanese islands, we have been able to demonstrate the significance of the $\mathrm{P}$ converted phases from upgoing $\mathrm{S}$ waves generated by three very deep (> $575 \mathrm{~km}$ ) events associated with Pacific Plate subduction. Such converted $\mathrm{P}$ phases modify the character of the $\mathrm{S}$ wavetrain and can carry large, longer-period ground motion to considerable distances from the source.

\section{Acknowledgements}

The computations were conducted using the Earth Simulator at Japan Marine Science and Technology Center (JAMSTEC), and the EIC parallel computer at the Earthquake Information Center at the Earthquake Research Institute, the University of Tokyo. We acknowledge the National Research Institute for Earth Science and Disaster Resilience (NIED) for the use of F-net, K-NET, and KiK-net records. We thank two anonymous reviewers and Editor for constructive comments, which were very helpful for the revision.

\section{Funding}

This study was conducted with support from Grants-in-Aid from the Japan Society for the Promotion of Science (No. 17 K01322).

\section{Availability of data and materials}

The F-net broadband records and K-NET/KiK-net strong motion records used in this study are available at the NIED Web page (http://www.seis.bosai.go.jp).

\section{Authors' contributions}

BLNK conducted the analysis of seismic waves and interpreted the data, and wrote the manuscript. TF collaborated with the first author in the construction of the manuscript, and conducted numerical simulations and assisted with drawing figures. All authors read and approved the final manuscript.

\section{Authors' information}

BLNK is Emeritus Professor of Seismology, The Australian National University. TF is a Professor at the Earthquake Research Institute, The University of Tokyo.

\section{Competing interests}

The authors declare that they have no competing interests.

\section{Publisher's Note}

Springer Nature remains neutral with regard to jurisdictional claims in published maps and institutional affiliations.

\section{Author details}

'Research School of Earth Sciences, Australian National University, Canberra, ACT 2600, Australia. ${ }^{2}$ Earthquake Research Institute, The University of Tokyo, 1-1-1 Yayoi, Bunkyo-ku, Tokyo 113-0032, Japan.

Received: 22 March 2019 Accepted: 4 June 2019

Published online: 09 July 2019

\section{References}

Chen M, Tromp J, Helmberger DV, Kanamori H (2007) Waveform modelling of the slab beneath Japan. J Geophys Res 112:B02305. https://doi.org/10. 1029/2006JB004394

Furumura T, Kennett BLN (2005) Subduction zone guided waves and the heterogeneity structure of the subducted plate: intensity anomalies in northern Japan. J Geophys Res 110:B10302. https://doi.org/10.1029/ 2004JB003486

Furumura T, Kennett BLN (2017) Unusual strong ground motion across Japan from the $680 \mathrm{~km}$ deep 30 May 2015 Ogasawara Islands earthquake. J Geophys Res Solid Earth 122:8143-8162. https://doi.org/10.1002/ 2017JB014519

Furumura T, Kennett BLN (2019) Regional to teleseismic strong ground motions from a 610 km deep 24 May 2013 Sea of Okhotsk earthquake. Abstract JpGU 2019 Meeting, SSS11-15, Chiba
Furumura T, Kennett BLN, Padhy S (2016) Enhanced waveguide effect for deepfocus earthquakes in the subducting Pacific slab produced by a metastable olivine wedge. J Geophys Res Solid Earth 121:6779-6796. https://doi.org/10. 1002/2016JB013300

Kennett BLN, Engdahl ER, Buland R (1995) Constraints on seismic velocities in the Earth from travel times. Geophys J Int 122:108-124

Kennett BLN, Furumura T (2010) Tears or thinning? Subduction structures in the Pacific plate beneath the Japanese Islands. Phys Earth Planet Inter 180:52-58. https://doi.org/10.1016/j.pepi.2010.03.001

Kuge K (2017) Seismic observations indicating that the 2015 Ogasawara (Bonin) earthquake ruptured beneath the $660 \mathrm{~km}$ discontinuity. Geophys Res Lett 44 10,855-10,862. https://doi.org/10.1002/2017GL074469

Laske G, Masters G, Ma Z, Pasyanos M (2013) Update on CRUST1.0—a 1-degree global model of Earth's crust. Geophys Res 15, Abstract:EGU2013-2658

Maeda T, Takemura S, Furumura T (2017) OpenSWPC: an open-source integrated parallel simulation code for modeling seismic wave propagation in 3D heterogeneous viscoelastic media. Earth, Planets and Space 69:102, https:// doi.org/10.1186/s40623-017-0687-2

Miller MS, Kennett BLN, Gorbatov A (2006) Morphology of the distorted subducted Pacific slab beneath the Hokkaido corner. Phys Earth Planet Inter 156:1-11

\section{Submit your manuscript to a SpringerOpen ${ }^{\circ}$ journal and benefit from:}

- Convenient online submission

- Rigorous peer review

- Open access: articles freely available online

- High visibility within the field

- Retaining the copyright to your article

Submit your next manuscript at $\boldsymbol{\nabla}$ springeropen.com 